\title{
THE INTERNATIONAL
}

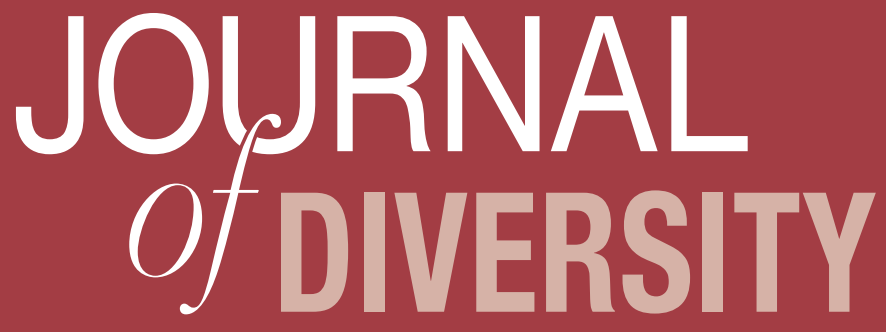

in Organizations,

Communities \& Nations

Volume 10, Number 3

Diversity in the Irish Workplace - Lesbian Women's Experience as Nurses

Mel Duffy 
THE INTERNATIONAL JOURNAL OF DIVERSITY IN ORGANISATIONS, COMMUNITIES AND NATIONS

http://www.Diversity-Journal.com

First published in 2010 in Champaign, Illinois, USA by Common Ground Publishing LLC www.CommonGroundPublishing.com.

(C) 2010 (individual papers), the author(s)

(C) 2010 (selection and editorial matter) Common Ground

Authors are responsible for the accuracy of citations, quotations, diagrams, tables and maps.

All rights reserved. Apart from fair use for the purposes of study, research, criticism or review as permitted under the Copyright Act (Australia), no part of this work may be reproduced without written permission from the publisher. For permissions and other inquiries, please contact

<cg-support@ @ommongroundpublishing.com>.

ISSN: $1447-9532$

Publisher Site: http://www.Diversity-Journal.com

THE INTERNATIONAL JOURNAL OF DIVERSITY IN ORGANISATIONS,

COMMUNITIES AND NATIONS is peer-reviewed, supported by rigorous processes of criterion-referenced article ranking and qualitative commentary, ensuring that only intellectual work of the greatest substance and highest significance is published.

Typeset in Common Ground Markup Language using CGCreator multichannel typesetting system

http://www.commongroundpublishing.com/software/ 


\title{
Diversity in the Irish Workplace - Lesbian Women's Experience as Nurses
}

\author{
Mel Duffy, Dublin City University, Ireland
}

\begin{abstract}
Work is an area which represents an important part of people's lives where they encounter the Other. It provides an individual with a sense of who they are in society, through their membership of communities. Through work, a lesbian woman's identity has to be negotiated as private lives and public lives can overlap. For lesbian women, work and identity intersect, providing a coherent sense of accomplishment. Research has shown that lesbian women are aware of the attitudes that prevail about lesbian women in the health care environment as they encounter them in their working lives: homophobia; lack of social support and understanding leading to non-disclosure of their own sexuality. Lesbian nurses work within the institution of medicine that reflects societal heterosexual norms. The methodology derived from the qualitative tradition employing hermeneutic phenomenology. It presents an original conceptualisation and consistent application of theoretical frameworks of Heidegger and Sartre. Interviews were conducted between March 2006 and April 2007 with seven lesbian nurses. Lesbian nurses in Ireland remain in the "closet" leading some lesbian nurses to experience social isolation. This paper argues that being oneself is difficult for lesbian nurses who work in the heteronormative culture of Irish hospitals.
\end{abstract}

Keywords: Lesbian, Nurses, Phenomenology, Health Care

\section{Introduction}

$\mathrm{W}$

ORK IS AN area which represents an important part of people's lives where they encounter the other. It provides an individual with a sense of who they are in society, through their membership of communities (Morgan 1999). Through work, a lesbian woman's identity has to be negotiated (Markowe 1996) as private lives and public lives can overlap. Clunis et al. (2005) suggest that for lesbian women, work and identity overlap, so providing a coherent sense of accomplishment. However, for some lesbian nurses, work is fraught with the unknown as to whether to hide one's sexuality, or reveal it for Others to see. This paper presents three lesbian women's experiences of being a nurse in Irish health care from a hermeneutical phenomenological perspective. A description of the theoretical and methodological approach adopted for this study is provided. Implications for policy are also discussed.

\section{Being Oneself in the Workplace}

'In order to get any truth about myself, I must have contact with another person. The other is indispensable to my own existence, as well as to my knowledge about myself' (Sartre 1985 p. 37-38). 
Sartre's (1985) philosophy suggests that to know oneself or to know the truth of oneself is to know oneself through the eye of the Other. I cannot become on my own, in isolation; I can only become when I interact with Others and understand their reactions towards me. I give meaning to these interactions based upon my knowledge of who I am or rather who I think I am and what Others think I am. Through this I get a sense of self. As Sartre (1985) indicates, an individual can only know her/himself through the intervention of the Other. Work is an area which represents an important part of people's lives where they encounter the Other. For lesbian women identities are likened to work, as it enables them to interact within society as workers, consumers and citizens. Work plays a major part in the experiences of people, giving them a sense of self, value and achievement. It is through work that we meet the Other and obtain a sense of who we are through the eye of the Other. By way of work the possibility of my becoming is open to me, through both my occupation and interactions with Others. As Markowe (1996) suggests, in relation to lesbian women 'coming out at work, type of job and work environment are pertinent' (p. 7). When a lesbian woman comes out at work, she needs to consider the environmental and social context in which this takes place, as they do not all value diversity.

\section{Lesbian Nurses: An Overview of the Literature}

A few studies have dealt with lesbian women's experiences of being nurses in the health care system (Giddings \& Smith 2001), or with their contribution to nursing care (White 2002). Giddings \& Smith's (2001) study suggests that lesbian nurses do not 'come out' at work, as they are aware that the nursing environment can be homophobic.

"Jane is not out to her patients and considers hospitals an unsafe place for persons who want to be open about their sexuality” (Giddings \& Smith 2001 p. 15).

Another respondent informed them that she chooses when and where to disclose her sexuality.

"Maggie chooses when to be 'out' in her job because she is aware that 'society and equally the health care environment, especially nursing, is homophobic',' (Giddings \& Smith 2001 p. 16).

However, lesbianism is visible in the nursing work environment through jokes, stereotypes and gossip, invisibility exists through either self-imposed or socially-imposed closeting (Giddings \& Smith 2001). This may be explained from the viewpoint that '[F]ew lesbians are able to escape the social stigma of having a sexual identity at odds with current mainstream cultural values' (Beals \& Peplau 2005 p. 146). Closeted lesbian nurses can collude with other health care professionals through participating in rituals that lead to stereotyping in order to keep their secret, thus conforming to the expectations of the dominant group, and thereby avoiding stigmatisation because of their lesbian identity. While they are avoiding overt discrimination by collusion, they are experiencing direct discrimination by being forced to remain closeted.

For lesbian nurses to 'come out' in the work environment requires basic trust, namely, trust in: 
"one's world and especially the persons who are its interpreters is crucial to one's sense of identity. It is for such reasons as these that shame may be said to go deeper than guilt; it is worse to be inferior and isolated than to be wrong, to be outcast in one's own eyes than to be condemned by society" (Lynd 1958 p. 207).

Through the internalisation of society's fears and anxieties about lesbianism, the lesbian woman may succumb to a feeling of shame, as Sartre (1969) puts it, 'I am ashamed of myself as I appear to the Other' (p. 222). Shame is internalised and can be dealt with by the self; guilt on the other hand can be sanctioned by society and penalised. Guilt finishes as it is the price paid for wrongdoing. In contrast, shame can arise out of an 'if-others-knew' syndrome, that is, 'we always imagine and in imagining share the judgments of the other mind' (Cooley 1968 p. 90). Through gossip and jokes the imagined judgments of the 'other mind' become a reality for lesbian nurses.

Lesbian nurses are aware that they lack the social support and understanding from their work colleagues, which is necessary for the maintenance of self-esteem (Beals \& Peplau 2005). It has been suggested that, 'identification with the majority culture does not preclude identification with the minority culture, and vice versa' (Fingerhut, Peplau \& Ghavami 2005 p. 130). Therefore, one may act in a social situation in a way that leads to the best outcome for the individual. By presenting oneself as an acceptable member of the majority culture, the lesbian woman is risking the outcome of a disclosure. If a lesbian nurse carries out her performances in work effectively, other nurses will not question her validity. But through the stereotypes, jokes and gossip the lesbian nurse faces 'unwilling acceptance of her [him]self by individuals who are prejudiced against persons of the kind $\mathrm{s} /[\mathrm{he}]$ can be revealed to be' (Goffman 1963 p. 58). Therefore the lesbian nurse tends to remain closeted and silent.

Shelby (1999) suggests that lesbian nurses should 'come out', arguing that while disclosure can be fraught, and the health benefits are greater. Equally, she indicates that if 'reputable' nurses 'come out', this would lead to other nurses questioning their biases. This however, is problematic: who decides who is 'reputable'? Moreover, there is no evidence that people question their biases based on new information (Harrison 2001). Most lesbians have had a lifetime experience of passing as heterosexuals, beginning from the moment they recognised their sexuality. However, this has been described as lesbians living a 'dual-identity', participating both in heterosexual and lesbian worlds (Fingerhut, Peplau \& Ghavami 2005). Dualidentity can be perceived as living "two lives", one that derives out of economic necessity, and the other in which lesbian women are socially connected with other lesbian women or others who affirm lesbian women's existence.

\section{Theoretical Framework}

The hermeneutical or interpretative phenomenological perspective was chosen as the framework for this study as it 'fits' with the aim to explore the lived experience of lesbian women as nurses in health care. Whilst a total of seven women were recruited for the study, in this paper insights from three women are presented on their experiences of being nurses in the health care environment.

The philosophy of both Heidegger (1962) and Sartre (1969), underpins this study. Heidegger's (1962) concern with being in the world, offers a theoretical framework whereby lesbian women can be seen as active participants in the world, creating understanding and 
meaning to their existence. The essence of Heidegger's phenomenology is 'Dasein' which he refers to as the human being in the world: 'The 'essence' of Dasein lies in its existence' (Heidegger 1962 p. 67). Johnson (2000) suggests that Heidegger views the human being as 'always involved in the practical world of experience' (p. 136). As Heidegger (1962 p. 86) indicates 'Being-in-the-world is a basic state of Dasein'. Being-in-the-world of health care for lesbian women as nurses is to know that world both as health care professionals and as lesbian women. They are aware of the attitudes to lesbian women that prevail in the health care environment, as they encounter them in their working lives: homophobia (Giddings \& Smith 2001); lack of social support and understanding (Fingerhut, Peplau \& Ghavami 2005) leading to non-disclosure of their own sexuality (Beals \& Peplau 2005), due to the covert or overt discrimination in the workplace.

Sartre (1969) offers us a lens through which we can examine how lesbian women experience the self as nurses. Sartre was interested in the question of subjectivity, suggesting that it was free, not constrained by religion or any other controlling factors, as an individual is not a means to an end, but an end itself. The individual must create her/himself. In particular I wanted to know how lesbian women remain lesbian within health care environment. It is this capturing of life as it is lived, that frames the articulation of understanding and meanings that lesbian women derive from the situations they find themselves in.

\section{Methodology}

This paper seeks to answer the question 'What is it like being a lesbian nurse in the health care environment?' Following ethical approval from Dublin City University Ethics Committee an advertisement to obtain a sample of lesbian nurses was placed on the National Council for the Professional Development of Nurses and Midwifery (NCNM) website in March 2006. The advertisement was also placed in the NCNM magazine edition in June 2006. Every registered nurse in Ireland receives the magazine. Data gathering took place between May 2006 and April 2007.

The techniques chosen for the purpose of data collection were that of 'insider' researcher by stating in the advertisement that I was a lesbian researcher and unstructured informal interviews. Initially in the data gathering process I wondered how much of myself I should give, however, it is the nature of research to give of the self (Letherby 2003). The interview process is a social interaction situation, and the more open I became about my own identity the more relaxed and forthcoming the participants became. 'It is in the co-disclosure of the shared world that issues of voice, reflexivity, identity, and understanding reveal themselves' (Kavanagh 2006 p. 252).

During the initial enquiry from potential participants we spoke about what my study was about and what I would like them to talk about. In this way they could think and reflect on their experiences in their own time and space, prior to the interview. The interview consisted of one question which invited the participant to reflect on her experience of health care, as a member of the nursing profession. The analysis of the data was guided by Heidegger's (1993) concept of dwelling, listening to the voices of lesbian women, moving forward in parts and taking refuge in other parts. Through writing and re-writing an interpretive text emerged.

Three voices of lesbian nurses are heard in this paper as they spoke about being lesbian in the workplace. These women were aged between 23 and 50 years. To disguise the identity 
of participants, pseudonyms of old Celtic Irish origin were used and are known as Finnsech, Grian and Saoirse.

\section{Limitations of the Study}

Hermeneutic phenomenology claims, meanings and understanding of everyday life 'are bound by context' (Esterfan, McAllister \& Rowe 2004 p.36). The findings of this study, conducted in Ireland, in 2006 with a small number of participants are not necessarily generalisable to other population groups. Van Manen (2002 p. 7) suggests hermeneutic phenomenology writing does 'not yield absolute truths, or objective observations' rather, 'at best gains an occasional glimpse of the meaning of human experience'. A phenomenological study is always 'one interpretation' which is presented here, that is my interpretation of the experiences of lesbian women.

\section{Findings}

This section analyses the themes that emerged from the interviews with lesbian nurses. The dominant theme is 'being different' in the workplace. Under the heading of diversity, the Health Service Executive staff handbook for all employees recognises that diversity in sexual orientation exists in society, and will be represented in their employees.

This section will explore whether those who are different are recognised in practice, and is divided into four parts: the first deals with the experience of being different in the Irish workplace; the second reviews break-time experience; the third explores the issues of the heterosexual dialogue; and finally, the fourth uncovers the mechanisms uses to negotiate the heterosexual dialogue.

\section{Being Different - the Irish Experience}

As providers of health care it is through the eye of the Other that lesbian women in their capacity as professional nurses obtain a sense of self. They obtain a sense of not only who they are, that is, lesbian women but also of what Others, in this case nurses, perceive lesbian women to be.

I suppose everybody, no matter how tough you are or no matter how self-assured you are, people's perceptions, especially when you are working with people matters you know, and how much you let them matter then is up to you. But working in the medical profession and certainly working within a very female-dominated profession leads to a wide variety of perceptions thrown in your direction (Finnsech).

Finnsech is aware that how people see her matters, she is not an island but interacts with Others. She suggests that individuals take onto themselves the perceptions of Others to varying degrees implying it is up to the individual to decide to what extent the opinions of Others replicates the self and their actions. This mirrors Goffman's (1963) assertions whereby Finnsech must 'face unwilling acceptance' of herself 'by individuals who are prejudiced against persons' (p. 28) who are like her, that is, lesbian women. 
Working in a dominantly female profession such as nursing brings Finnsech's awareness of her lesbianism to the fore. She indicates that there are a 'wide variety of perceptions' about lesbian women amongst the nursing profession.

"What does not vary is the necessity for her (him) to exist in the world, to be at work there, to be there in the midst of other people, and to be mortal there" (Sartre $1985 \mathrm{p}$. 8).

Finnsech exists in the world that is populated by Others. She cannot exist on her own she needs the Other for her existence to be apparent. Through her existence Finnsech is aware of her lesbian identity in everyday situations; however through her work as a nurse her identity can come to the forefront. Due to this she is aware of the perceptions of her colleagues towards lesbian women.

\section{Break-time Chatter}

Finnsech's coming out at work was not intentional or planned. Rather, she found herself in a place where she did not want to be other than herself.

A specific incidence I remember was we had been on a set of nights with a group that I, with about 4 of us that I had worked with for about 6 months so, I wasn't out at this point to these particular colleagues and we had done a weeks nights and everything is very laid back and personal when you're working nights over Christmas, people talk about their families, where they'd rather be you know and you spend, your longer breaks, you spend a lot more time sort of discussing your personal lives (Finnsech).

Finnsech reveals that Christmas time at work leads to different conversations and more sharing of personal lives amongst nursing colleagues. Although predominantly a Christian religious ritual, Christmas in Irish culture through the dominant position of the Catholic Church epitomises the family. It reinforces the norms and values of the heterosexual family recognising no other family structures. It underpins what Tovey \& Share (2000) indicates as the importance of 'religion in the shaping of our contemporary society, its continuing relevance in terms of everyday social life' (p. 306). The relevance of Christmas for Irish society is that it is one of many rituals that is seen as traditionally focusing on the heterosexual family as the primary unit of society. Nassbaum (1997) succinctly states: 'society shapes not only tradition, but also the experience of people who grow up in it' (p. 229). The Christmas period in Ireland is traditionally a time for families whether or not an individual participates in the religious ritual. Finnsech experienced more exchanges being initiated around family.

\section{Heterosexual Dialogue}

Finnsech experienced Christmas, as the time when private and public lives collided through talk between colleagues other lesbian nurses perceive this as being part and parcel of normal every day talk amongst nurses. 
I find it very hard at break-times, all we seem to talk about are weddings and engagements, babies and what schools to send your children to and I just find its very draining listening to it all the time (Saoirse).

Another participant put this in an alternative way.

I was kind of looking at how you know social aspect in work and I suppose you have to sit down, you have to listen to I mean the young ones are all getting married and all about their dresses and all about for half the night and photographs and then the women and men my age then would be with their children and their photographs and then the older ones would be about their extensions as well but it does get a bit boring I mean some people who ask me oh are you going out with anybody (Grian).

Grian and Saoirse experience their difference on an ongoing base through day-to-day conversations. Saoirse faces social conversations in her workplace as being 'very hard' and 'draining' as she is listening to discussions she cannot participate in. She is socially isolated from her peers, as she does not fit into the rituals of the heterosexual norm that is engagements, weddings, babies, children and schools. These are the tools as Saoirse experiences it of the heterosexual dialogue. Her lived reality does not include these rituals on a personal level. She expresses this in the following manner:

I feel very different to the other nurses ... don't have a lot in common with the other nurses (Saoirse).

Heidegger (1969) suggests 'this thing that is called differences, we encounter it everywhere' (p. 63). Saoirse experiences her differences on a daily basis in the workplace. Her present situation does not include the reality of family life that is portrayed to her from her colleagues as the heterosexual norm. There is no recognition of same-sex family structures in Irish society. While lesbian women are having children, and some have children from being previously married, they are creating their own family structures; but this is not part of Saoirse's reality. She feels different to her colleagues, encapsulating this by stating that she does not 'have a lot in common with the other nurses'. She views her colleagues as being Others through which she can judge herself but more importantly be judged (Sartre 1969). She cannot participate fully in the day-to-day exchanges that happen between colleagues at break time. However her difference is exposed for her to see and while her colleagues may not know this Saoirse does. In Sartrean terms it is through the Other that she knows herself.

Grian on the other hand views talk amongst nurses at break-time as a chore in that she states 'you have to' both 'sit down' and 'listen' to the stories that are shared at break times. It is almost like a weight on her shoulders or a burden whereby the 'you have to' indicates that there is no escaping and it is a duty to be performed. As Skidmore (2004) succinctly puts it:

"[F]or many workers a distinguishing feature of the workplace is the regular, if not daily, contact with a group of co-workers with whom one is obligated to interact" (p. 236). 
As Grian cannot participate in these exchanges she finds them 'a bit boring'; in other words for Grian these conversations are tiresome and tedious. They are also repetitive whereby she can almost predict what the topic at break-times will be.

\section{Negotiating the Heterosexual Dialogue}

Grian finds ways around questions about her personal life particularly in relation to marriage and children. She finds her route by not participating in the conversation on the self and turning it back on the questioner.

By not talking about yourself and asking, I suppose asking them questions, and they are talking about themselves then (Grian).

She removes the focus from herself and orientates the Other towards themselves through asking them questions about the self. In this way she negotiates the presentation of the self in front of the heterosexual norm. Grain puts distance between herself and Others by placing the spotlight on the Other and removing it from herself. She not only successfully distances herself from the Other but from the assigned categories that make up heterosexuality. In this way she successfully keeps her lesbianism hidden. Grian reflects

I'm a listener more than a talker (Grian).

She positions herself favourably for the Other as being a listener. In this way she does not have to interact on a personal level with her colleagues. She successfully deflects any queries about herself and becomes the ear for Others to talk about themselves. By being a listener Grian regulates information about the self.

Grian's actions could be interpreted from a Sartrean point of view as the hiding of the self.

"My possibility of hiding in the corner becomes the fact that the Other can surpass it toward his possibility of pulling me out of concealment, of identifying me, of arresting me" (Sartre 1969 p. 264).

Grian's hiding in the corner is the act of turning the conversation away from herself to the Other. The act of listening prevents her discovery and the ability of the Other to see her as a lesbian woman. Equally she does not become 'this self that the other knows' (Sartre 1969 p. 261). As she does not disclose herself there is no opportunity for the Other to know her. Grian's concealment remains. This adequately illustrates Draucker's (1999) point when he states that individuals participate in acts of 'everyday skilful coping' (p. 361). Those are the skills for everyday living which enable an individual to participate in the situations in which they find themselves. One of the skills that Grian has developed for everyday living in her capacity as a nurse, which enables her to exist within the nursing community is that of listener. By becoming a listener she does not have to participate by divulging the self, she can remain 'hidden from the Other' (Sartre 1969 p. 49) but is perceived as participating in the conversation. Grian, however, does participate in the conversation through asking questions of the Other and listening. This is different for Saoirse as she indicates that she does not take part because she lacks commonality with her colleagues. For her there is nothing to discuss and the possibility of her becoming through interaction with Others is limited. 
However Grian's possibility of becoming is equally limited through her interactions or lack of interaction with the Other.

\section{Summary of Findings}

Being oneself for lesbian nurses working in an Irish health care setting is a troublesome affair. Lesbian nurses in this study employed mechanisms to hide their sexuality, such as being a listener. These lesbian nurses, remained in the closet. The experience of being different for some lesbian nurses was heightened through the heteronormativity of conversations amongst nurses.

\section{Implications for the Workplace}

The HSE recognises through its Employee Handbook diversity in sexual orientation. However, the findings of this study would suggest that they need to develop and implement training for all health care professionals to create a working policy (www.hse.ie). In Ireland, the National Council for the Professional Development of Nursing and Midwifery (NCNM) was set up in 1999, with the mission to develop the nursing and midwifery profession whereby the profession could delivery nursing care in a changing health care environment.

The NCNM are the nursing body in Ireland that can issues guidelines for best nursing practice. However, through the promotion of quality of health care, the NCNM needs to recognise and develop guidelines on lesbian health care. While this plan was developed prior to the establishment of the HSE, it is the responsibility of the HSE to ensure that both a woman-friendly health care, and sensitivity training programmes are established, for all health care professionals. To date, neither the HSE nor the NCNM have developed best practice guideline for the care of lesbian patients. While the HSE recognises the existence of sexual diversity amongst health care professionals, it needs to create a working policy.

\section{Conclusion}

Being members of the nursing profession the majority of the participants faced their difference on day-to-day bases revealing a profession that did not acknowledge diversity amongst its members. However it is pertinent to keep in mind Skidmore's (2004) observation that when we review the experiences of lesbian women of the workplace the 'contours of the heteronormative workplace are thrown into somewhat sharper relief than would otherwise be the case' (p.233). In other words lesbian women as nurses practice in a cultural environment whereby the norms, values and belief systems of nursing are based upon heterosexuality.

This paper aimed to explore the meanings and understanding that lesbian women generate working in a health care environment as nurses. It gives meaning and understanding to the experiences that lesbian women provide as nurses, within the health care environment.

\section{Acknowledgements}

This study was part-funded by the Irish Research Council for Humanities and Social Science Postgraduate Scholarship 2006-2007. 


\section{References}

Beals, Kristin P. \& Peplau, Letitia Anne (2005) Identity Support, Identity Devaluation, and Well-Being Among Lesbians. Psychology of Women's Quarterly, 2, pp140-148.

Clunis, D. Merilee; Fredriksen-Goldsen, Karen I.; Freeman, Pat A. \& Nystrom, Nancy (2005) Lives of Lesbian Elders: Looking Back, Looking Forward. New York: The Haworth Press.

Cooley, Charles H. (1968) The social Self: On the Meaning of 'I'. In The Self in Social Interaction: classic and Contemporary Perspectives (eds. Gordon, Chad \& Gergen, Kenneth J.) pp8791 London: John Wiley and Sons, Inc.

Draucker, Claire Burke (1999) The Critique of Heideggerian Hermeneutical Nursing Research. Journal of Advanced Nursing 30, 2, pp360-373.

Estefan, Andrew; McAllister, Margaret \& Rowe, Jennifer (2004) Difference, Dialogue, Dialectics; A Study of Caring and Self-Harm. In 2004 Many Voices: Towards Caring Culture in Healthcare and Healing; Interpretive Studies in Healthcare and in Human Sciences (eds. Kavanagh, Kathryn H. \& Knowlden, Virginia) pp21-61, Madison:The University of Wisconsin Press.

Fingerhut, Adam, W.; Peplau, Letitia Anne \& Ghavami, Negin (2005) A Dual-Identity Framework for Understanding Lesbian Experience. Psychology of Women Quarterly, 29, pp129-139.

Giddings, Lynne S. and Smith, Marlaine C. (2001) Stories of Lesbian In/Visibility in Nursing. Nursing Outlook, 49, 1, pp14-19.

Goffman, Erving (1963) Stigma London: Penguin Books.

Harrison, Jo (2001) 'It's None of my Business': Gay and lesbian Invisibility in Aged Care. Australian Occupational Therapy Journal, 48 pp142-145.

Heidegger, Martin (1993) Building Dwelling Thinking. In Martin Heidegger: Basic Writings (ed. Krell, Davil) pp343-363 Harper San Francisco.

Heidegger, Martin(1962) Being and Time translated by John Macquarrie and Edward Robinson Harper and Row, Publishers, Incorporated: New York.

Johnson, Mary E. (2000) Heidegger and Meaning: Implications for Phenomenological Research. Nursing Philosophy 1, pp134-146.

Kavanagh, Kathryn H. (2006) Beyond the Individual: Healthcare Ethics in Diverse Societies. In Listening to the Whispers: Re-thinking Ethics in Healthcare (eds. Sorrell Dinkins, Christine \& Sorrell, Jeanne Merkle) pp248-304 Madison: The University of Wisconsin Press.

Letherby, Gayle (2003) Feminist Research in Theory and Practice. Buckingham: Open University Press.

Lynd, Helen M. (1958) On Shame and the Search for Identity. New York: A Harvest Book.

Markowe, Laura A. (1996) Redefining the Self: Coming Out as Lesbian. Cambridge: Polity Press.

Morgan, Glenn (1999) Work and Organisations. In Sociology: Issues and Debates (ed. Taylor, Steve) pp208-230 London: MacMillan Press Ltd.

Nussbaum, Martha C. (1997) Cultivating Humanity: A Classical Defense of Reform in Liberal Education. London: Harvard University Press.

Sartre, Jean-Paul (1969) Being and Nothingness: An Essay on Phenomenological Ontology translated by Barnes, Hazel E. London: Routledge.

Sartre, Jean-Paul (1985) Existentialism and Human Emotions. New York: Citadel Press.

Skidmore, Paul (2004) A Legal Perspective on Sexuality and Organization: A lesbian and Gay Case Study. Gender, Work and Organization, 11, 3, pp229-253.

Van Manen, Max (2002) Writing in the Dark: Phenomenological Studies in Interpretive Inquiry Ontario: The Althouse Press.

White, Isabel (2002) Nursing as a Sexualised Occupation. In The Challenge of Sexuality in Health Care (eds. Heath, Hazel \& White, Isabel) pp51-65 Oxford: Blackwell Science. 


\section{About the Author}

Dr. Mel Duffy

Mel Duffy is a Sociology lecturer in the School of Nursing, Dublin City University. She obtained her Ph.D. in 2008 in the School of Language and Intercultural Studies, Dublin City University. The title of her thesis was "Voices from the Hinterland: Lesbian Women's Experience of Irish Health Care". Her research interests include lesbian health and health care; inequalities in health care; marginalisation in health care; hermeneutic phenomenology and existentialism. 



\section{EDITORS}

Mary Kalantzis, University of Illinois, Urbana-Champaign, USA.

Paul James, Globalism Institute, RMIT University, Australia

\section{EDITORIAL ADVISORY BOARD}

Ien Ang, University of Western Sydney, Sydney, Australia.

Joanna van Antwerpen, Research and Statistics, Amsterdam, The Netherlands.

Samuel Aroni, University of California, Los Angeles, USA.

Susan Bridges, University of Hong Kong, Hong Kong.

Duane Champagne, University of California, Los Angeles, USA.

Guosheng Y. Chen, RMIT University, Melbourne, Australia.

Jock Collins, University of Technology, Sydney, Australia.

Bill Cope, University of Illinois, Urbana-Champaign, USA.

Heather Marion D'Cruz, Deakin University, Geelong, Australia.

James Early, Smithsonian Institution, Washington, D.C., USA.

Denise Egéa-Kuehne, Louisiana State University, Baton Rouge, USA.

Amareswar Galla, University of Queensland, Brisbane, Australia.

Grethe van Geffen, Seba Cultuurmanagement, Amsterdam, The Netherlands.

Barry Gills, Newcastle University, Newcastle upon Tyne, UK.

Jackie Huggins, University of Queensland, Brisbane, Australia.

Andrew Jakubowicz, University of Technology, Sydney, Australia.

Paul James, Globalism Institute, RMIT University, Melbourne, Australia.

Ha Jingxiong, Central University of Nationalities, Beijing, China.

Mary Kalantzis, University of Illinois, Urbana-Champaign, USA.

Jack Levin, Northeastern University, Boston, USA.

Cristina Poyatos Matas, Griffith University, Brisbane, Australia.

Peter McLaren, University of California, Los Angeles, USA.

Joe Melcher, Xavier University of Louisiana, New Orleans, USA.

Greg Meyjes, Solidaris Intercultural Services, Falls Church, USA.

Walter Mignolo, Duke University, Durham, USA.

Brendan O'Leary, University of Pennsylvania, Philadelphia, USA.

Aihwa Ong, University of California, Berkeley, USA.

Peter Phipps, Globalism Institute, RMIT University, Melbourne, Australia.

Ronald Prins, Bos en Lommer Neighbourhood Council, Amsterdam-West, The Netherlands.

Peter Sellars, University of California, Los Angeles, USA.

Michael Shapiro, University of Hawai'i, Manoa, USA.

David S. Silverman, Kansas Wesleyan University, Salina, USA.

Martijn F.E. Stegge, Diversity Platform, Amsterdam, The Netherlands.

Geoff Stokes, Institute for Citizenship and Globalisation, Deakin University, Melbourne, Australia.

Terry Threadgold, Cardiff University, Wales, UK.

Mililani Trask, Permanent Forum on Indigenous Issues for the Economic Council of the UN Assembly, Hawai'i, USA.

Marij Urlings, Inholland University, Amsterdam-Diemen, The Netherlands.

Rob Walker, Keele University, Keele, UK.

Ning Wang, Tsinghua University, Beijing, China.

Owens Wiwa, African Environmental and Human Development Agency, Toronto, Canada. 


\section{THE UNIVERSITY PRESS JOURNALS}

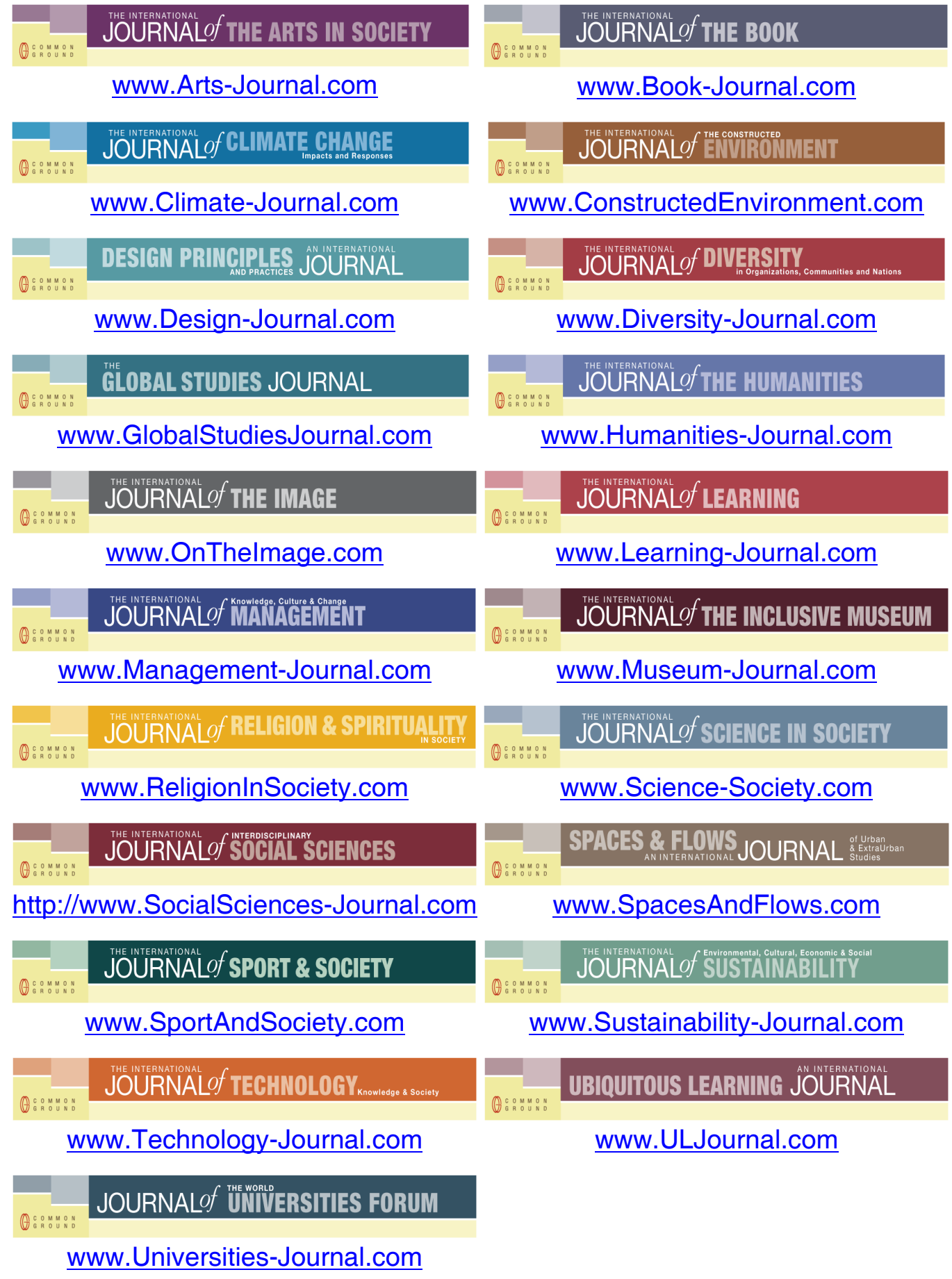

FOR SUBSCRIPTION INFORMATION, PLEASE CONTACT subscriptions@commongroundpublishing.com 